\title{
Neonatal mortality rates in Brazilian municipalities: from 1996 to 2017
}

\author{
Lais Baroni ${ }^{1} \mathbb{1}$, Rebecca Salles ${ }^{1,2}$, Samella Salles ${ }^{4}$, Marcel Pedroso², Jefferson Lima², Igor Morais 1,2, \\ Lucas Carraro², Raphael de Freitas Saldanha², Carlos Sousa², Carlos Cardoso², Balthazar Paixño ${ }^{1,2}$, Sérgio Cruz², \\ Eduardo Ogasawara', Patrícia de Morais Mello Boccolini ${ }^{3}$ and Cristiano Siqueira Boccolini $3^{*}$
}

\begin{abstract}
Objectives: Neonatal mortality is a global public health problem, and the efforts to reduce child mortality is one of the goals of the 2030 Agenda for Sustainable Development, launched in 2015 by the United Nations. The availability of historical neonatal mortality rates (NMR) data in Brazilian municipalities is crucial to evaluate trends at local, regional and national level, identifying gaps and vulnerable territories. Therefore, the objective of this article is to offer an integrated dataset containing monthly data in a historical series from 1996 to 2017 with information on all births, neonatal deaths, and NMR (total, early and late components) enriched with information related to the municipality.
\end{abstract}

Data description: It is a dataset of historical data with information on the number of births, the number of neonatal deaths, the neonatal mortality rate (including early and late), and geographic information for each month (between January 1996 and December 2017) and Brazilian municipality.

Keywords: Neonatal mortality rate, Time series data, Brazilian municipalities

\section{Objectives}

Neonatal mortality, defined as the number of deaths of children from 0 to 27 days of life per thousand live births, represents a global public health problem [1]. The neonatal mortality rate (NMR) has dropped in Brazil from 37 deaths per thousand live births in 1990 to 18 deaths per thousand live births in 2017, a significant reduction of $51 \%$. Nonetheless, these values represent the deaths of 272,439 Brazilian newborns in the last 10 years [2-4].

Reducing neonatal mortality is an essential part of efforts to reduce child mortality and corresponds to a goal of the 2030 Agenda for Sustainable Development, launched in 2015 by the United Nations [5]. The third Sustainable Development Goal (SDG) aims to "end, by 2030, preventable deaths of newborns and children under 5 years of age, with all countries aiming to reduce

*Correspondence: cristiano.boccolini@icict.fiocruz.br

${ }^{3}$ Oswaldo Cruz Foundation, Fiocruz, Rio de Janeiro, Brazil

Full list of author information is available at the end of the article neonatal mortality to at least as low as 12 deaths per 1000 live births and under- 5 mortality to at least as low as 25 deaths per 1000 live births".

In the epidemiology, the process of knowledge discovery in databases (KDD) can assist in the determination of public policies to be implemented, such as improving neonatal care or adopting pro-breastfeeding techniques [6]. The datasets presented in this document are directed precisely at this objective. They can easily be integrated with additional information such as population density, human development index (HDI), quality of prenatal care, among others. Therefore, this work's main contribution is to provide a consolidated historical datasets with information related to neonatal mortality in Brazilian municipalities.

\section{Data description}

Since mothers can live in one municipality and have delivery in another one, in this work, two datasets built analogously containing the same attributes are 
Table 1 Overview of data files/datasets

\begin{tabular}{llll}
\hline Label & Name of data file/dataset & File type (file extension) & Data repository and identifier \\
\hline Dataset 1 & NM_County_B & Delimited text (.csv) & Synapse: https://doi.org/10.7303/syn22241002 [7] \\
Dataset 2 & NM_County_R & Delimited text (.csv) & Synapse: https://doi.org/10.7303/syn222241002 [7] \\
Data file 1 & Dict_NM_county & Delimited text (.csv) & Synapse: https://doi.org/10.7303/syn22241002 [7] \\
Data file 2 & Data_construction & Portable document (.pdf) & Synapse: https://doi.org/10.7303/syn22241002 [7] \\
Data file 3 & Data_validation & R code (.r) & Synapse: https://doi.org/10.7303/syn22241002 [7] \\
Data file 4 & Municipalities_codes_IBGE & Delimited text (.csv) & Synapse: https://doi.org/10.7303/syn22241002 [7] \\
Data file 5 & Data_construction & Jupyter notebook (.ipynb) & Synapse: https://doi.org/10.7303/syn22241002 [7] \\
Data file 6 & ETLTMNOCOR & Dataiku DSS project (.zip) & Synapse: https://doi.org/10.7303/syn22241002 [7] \\
Data file 7 & ETLTMNRES & Dataiku DSS project (.zip) & Synapse: https://doi.org/10.7303/syn22241002 [7] \\
Data file 8 & Data_translation & Jupyter notebook (.ipynb) & Synapse: https://doi.org/10.7303/syn22241002 [7] \\
\hline
\end{tabular}

available: NM_County_B and NM_County_R. While in $N M \_C o u n t y \_B$, the instances correspond to the municipality of birth of the neonates, in NM_County_R, the instances correspond to the municipality where the neonate's mother lives, both for each available competency date. These datasets and related files are available for download, as shown in Table 1.

\section{Data construction}

The datasets developed are the result of a construction process organized into three main activities: (i) data integration, (ii) creation of neonatal mortality rates, and (iii) data enrichment. The criteria adopted for data management were based on detailed studies of the dataset and the support of specialists in the field. ${ }^{1}$

i. The developed datasets integrate data from the Live Birth Information System (SINASC) and the Mortality Information System (SIM). Both are made available by DATASUS and represent individual records of live births and deaths. Such records were aggregated by competency date (month and year) and municipality (place of birth and mother's residence), creating absolute values with the total number of births and deaths. SIM data were filtered, selecting only neonatal deaths, and then separated into general (0-27 days), early (0-7 days) and late (8-27 days) neonatal deaths.

ii Other temporal aggregations (semiannual and annual moving average) and spatial aggregations (states, regions, and country) were constructed from the absolute values of births and neonatal deaths. Then, the general, early, and late neonatal mortality rates (NMR) were calculated for each

\footnotetext{
${ }^{1}$ Description of the construction of the datasets is available at https://www. synapse.org/\#!Synapse:syn22288740
}

instance aggregated in time (month, semiannual, and annual moving average) and space (municipalities, states, regions, and country) according to Eq. 1.

$$
\mathrm{NMR}=\frac{\text { number of neonatal deaths }}{\text { number of births }} \cdot 1000(1)
$$

iii. The data was enriched with information about the municipalities, states, and regions obtained from the DATASUS FTP server. ${ }^{2}$ The attributes resulting from this process are the coordinates, area, regional health codes, and Boolean attributes, indicating if the municipality is the state's capital, border. The data dictionary ${ }^{3}$ presents a full description.

\section{Data validation}

The datasets NM_County_B and NM_County_R present, respectively, 845,561 and 1,413,773 records and 106 attributes. There are 36 attributes regarding the number of deaths. There is an attribute for each combination in time (month, moving average, and year), space (municipality, federation state, region, and country), and type of neonatal death (general, late, and early). Thirty-six attributes associated with rates also exist, analogous to those of deaths. The attributes regarding births differ due to not having the distinction of the type of delivery and. Therefore, they are 24 . There are 18 attributes with information about the municipalities. There are still the attributes year, month, and year/month in timestamp format. ${ }^{4}$

\footnotetext{
${ }^{2}$ Available at ftp://ftp.datasus.gov.br/dissemin/publicos/SINASC/NOV/ TABELAS/.

3 Available at https://www.synapse.org/\#!Synapse:syn22241065.

4 The timestamp format represents the seconds since the date of origin, 01/01/1970.
} 
In NM_County_B, approximately $66 \%$ of the municipalities have more than half of the competency dates, and a little more than $44 \%$ have more than $90 \%$. In $N M \_C o u n t y \_R$, almost all municipalities (99.8\%) have more than half of the competency dates, and a little more than $88 \%$ have more than $90 \%$. NM_County_B includes 4998, and NM_County_R comprises all municipalities of the 5570 existing in Brazil. The differences among two datasets exists due not all municipalities in Brazil have birth delivery facilities or maternity wings, forcing mothers to have their babies in surrounding cities.

\section{Limitations}

- Some municipalities do not have a complete historical series and may only have data corresponding to a short period or with very sparse intervals. This happens because $68 \%$ of Brazilian municipalities had less than 20 thousand inhabitants, increasing the number of months without births, and subsequent absence of NMR.

- There are cases where the rates exceed one thousand, that represents more deaths than births. These results may reflect the death of a baby in a month without births. We suggest, during analysis, the addition of a filter to ignore the NMR above 200/1000 births.

- NM_County_B does not include all municipalities of the country since not all have maternity hospital or birth delivery facilities.

- Since neonatal deaths are a relatively rare event, and many of Brazilian municipalities have populations with less than 20,000 inhabitants, for the vast majority of competency dates, the number of neonatal deaths in the municipality is equal to zero. It makes the corresponding NM_County_R also equal to zero. In NM_County_B, 81.13\% of the records have a monthly NM_County_R equal to zero. In $N M \_C o u n t y \_R$, the percentage is $78.21 \%$.

- The municipalities of Aroeiras do Itaim, Figueirão, Ipiranga do Norte, and Itanhangá were created on January 1st, 2005. Therefore, it was not possible to find information on coordinates and area for them. These are the only empty fields (NAs) in the datasets.

\footnotetext{
Abbreviations

NMR: Neonatal mortality rate; DATASUS: Department of Informatics of the Unified Health System of Brazil; SUS: Unified Health System; SINASC: Brazil Live Birth Information System; SIM: Brazil Mortality Information System; KDD: Knowledge Discovery in Databases.
}

Acknowledgements

Not applicable.

\section{Authors' contributions}

All authors contributed equally to the study. CB; PB conceptualized the study design, MP; JL; IM; LC; RF; BP acquired the data, LB; RS; EO conducted data analysis and interpretation. Furthermore SS; CS; CC; SC revised it critically for intellectual content. All authors read and approved the final manuscript.

Funding

Bill \& Melinda Gates Foundation and national council for scientific and technological development (CNPq).

\section{Availability of data and materials}

The dataset generated during the current study and additional documentation is freely and openly available on the Synapse repository at https://doi. org/10.7303/syn22241002 [7].

\section{Ethics approval and consent to participate}

The datasets used in this study were provided by DATASUS. The Ministry of Health of Brazil is committed to respect the ethical precepts and to guarantee the privacy and reliability of the data.

\section{Consent for publication}

Not applicable.

\section{Competing interests}

The authors declare that they have no competing interests.

\section{Author details}

1 Federal Center for Technological Education of Rio de Janeiro, CEFET/RJ, Rio de Janeiro, Brazil. ${ }^{2}$ Platform of Data Science Applied to Health (PCDaS), ICICT, Oswaldo Cruz Foundation, Fiocruz, Rio de Janeiro, Brazil. ${ }^{3}$ Oswaldo Cruz Foundation, Fiocruz, Rio de Janeiro, Brazil. ${ }^{4}$ Federal Institute of Rio de Janeiro, IFRJ, Rio de Janeiro, Brazil.

Received: 21 October 2020 Accepted: 31 December 2020

Published online: 09 February 2021

\section{References}

1. Lawn JE, Cousens S, Zupan J. 4 million neonatal deaths: when? where? why? Lancet. 2005;365(9462):891-900.

2. Wardlaw T, You D, Hug L, Amouzou A, Newby H. Unicef report: enormous progress in child survival but greater focus on newborns urgently needed. Reprod Health. 2014;1 1(1):1-4.

3. Hug L, Alexander M, You D, Alkema L, for Child Mortality Estimation UI-aG. National, regional, and global levels and trends in neonatal mortality between 1990 and 2017, with scenario-based projections to 2030: a systematic analysis. Lancet Glob Health. 2019;7(6):710-20.

4. DATASUS: information systems on live births and mortality. Brazilian Ministry of Health; 2020. http://svs.aids.gov.br/dantps/centrais-de-conte udos/paineis-de-monitoramento/mortalidade/infantil-e-fetal.

5. UN: sustainable development goals; 2020. https://www.un.org/sustainabl edevelopment/development-agenda.

6. Victora CG, Bahl R, Barros AJD, França GVA, Horton S, Krasevec J, Murch S, Sankar MJ, Walker N, Rollins NC, Allen K, Dharmage S, Lodge C, Peres KG, Bhandari N, Chowdhury R, Sinha B, Taneja S, Giugliani E, Horta B, Maia F, de Mola CL, Hajeebhoy N, Lutter C, Piwoz E, Martines JC, Richter L. Breastfeeding in the 21st century: epidemiology, mechanisms, and lifelong effect. Lancet. 2016;387(10017):475-90.

7. Baroni L, Salles R, Salles S, Pedroso M, Lima J, Morais I, Carraro L, Saldanha R, Sousa C, Cardoso C, Paixño B, Cruz S, Ogasawara E, Boccolini P, Boccolini C. Dataset of monthly historical record of neonatal mortality rates in Brazilian municipalities. Synapse. 2020. https://doi.org/10.7303/syn22 241002.

\section{Publisher's Note}

Springer Nature remains neutral with regard to jurisdictional claims in published maps and institutional affiliations. 